
\title{
$\begin{array}{ll}\text { Research Square } & \begin{array}{l}\text { Preprints are preliminary reports that have not undergone peer review. } \\ \text { They should not be considered conclusive, used to inform clinical practice, } \\ \text { or referenced by the media as validated information. }\end{array}\end{array}$
}

\section{Indication-prescription study for the management of conjunctivitis in a Colombian population}

\author{
Luis Fernando Valladales-Restrepo \\ Universidad Tecnologica de Pereira \\ Manuel Enrique Machado-Duque \\ Universidad Tecnológica de Pereira: Universidad Tecnologica de Pereira \\ Andrés Gaviria-Mendoza \\ Universidad Tecnológica de Pereira: Universidad Tecnologica de Pereira \\ Diana Fiorella López-Caicedo \\ Universidad Tecnológica de Pereira: Universidad Tecnologica de Pereira \\ Juan Alberto Ospina-Cano \\ Universidad Tecnológica de Pereira: Universidad Tecnologica de Pereira \\ María Camila Oyuela-Gutiérrez \\ Fundación Universitaria Autónoma de las Américas: Fundacion Universitaria Autonoma de las Americas \\ Dayron Fernando Martínez-Pulgarín \\ Universidad Nacional de Colombia \\ Jorge Enrique Machado-Alba ( $\nabla$ machado@utp.edu.co) \\ Universidad Tecnologica de Pereira Facultad de Ciencias de la Salud https://orcid.org/0000-0002-8455-0936
}

Research Article

Keywords: Conjunctivitis, Anti-Bacterial Agents, Glucocorticoids, Inappropriate Prescribing, Pharmacoepidemiology, Colombia.

Posted Date: February 14th, 2022

DOI: https://doi.org/10.21203/rs.3.rs-1300227/v1

License: @ (i) This work is licensed under a Creative Commons Attribution 4.0 International License. Read Full License 


\section{Abstract}

Purpose: Conjunctivitis is one of the most common ocular pathologies. Its treatment depends on its etiology, but an excessive use of antibiotics and corticosteroids, which in many cases are contraindicated, has been described. The objective was to describe the prescription patterns of medications used to treat conjunctivitis in a Colombian population.

Methods: This was a cross-sectional study on the pharmacological treatment of patients diagnosed with conjunctivitis based on a drug-dispensing database of approximately 8.5 million people affiliated with the Colombian Health System. Some sociodemographic and pharmacological variables and comorbidities were considered. A descriptive analysis was performed.

Results: A total of 8,708 patients were identified; they had a median age of 44.7 years, and $59.3 \%$ were women. The most common causes of conjunctivitis were unspecified (53.1\%) and allergic (37.4\%). The most commonly used drug was olopatadine (26.1\%), followed by dexamethasone with neomycin and polymyxin B (25.0\%). A total of $97.0 \%$ of the patients received ophthalmic prescriptions, while $12.8 \%$ received systemic medications. Glucocorticoids (40.3\%), antibiotics (37.7\%) and antihistamines (31.7\%) were the most commonly used groups of ophthalmic drugs. Glucocorticoids and ophthalmic antibiotics were the medications most frequently prescribed by general practitioners for the treatment of viral or bacterial conjunctivitis.

Conclusions: Many patients with conjunctivitis are not being managed according to the recommendations of clinical practice guidelines, which highlights that the widespread use of antibiotics with ophthalmic glucocorticoids could be considered potentially inappropriate prescriptions in many cases.

\section{Introduction}

Conjunctivitis is the inflammation or infection of the conjunctiva and is characterized by dilation of the conjunctival vessels that leads to hyperemia, edema, pain and ocular discharge $[1,2]$. It is the most common ocular pathology, representing approximately $2.0 \%$ of all primary care consultations and $1.0 \%$ of emergency consultations [1, 3], and the majority of patients are initially managed by primary care physicians instead of ophthalmology professionals [1]. Its prevalence varies according to the underlying cause, the age of the patient and the season of the year [1]. However, in general, viral and allergic causes are the most frequent etiologies $[1,4,5]$.

Conjunctivitis can be classified according to its etiology, chronicity and severity. In this way, conjunctivitis can be infectious (viral, bacterial or parasitic) or noninfectious (allergic, mechanical, irritative, toxic, immune-mediated or neoplastic); acute (lasting less than 4 weeks) or chronic (lasting more than 4 weeks); and mild or moderate/severe according to the intensity of its clinical manifestations [2, 4, 5]. Its treatment depends mainly on the underlying etiology; however, definitive diagnosis is a great challenge in making the definitive diagnosis due to the overlap of symptoms and the heterogeneous clinical presentation, and studies have shown a clinical inaccuracy rate that oscillates between 40.0 and $75.0 \%$ [3] and contributes to the inadequate management of patients [6].

Excessive use of ophthalmic antibiotics and glucocorticoids has been shown in patients with conjunctivitis [6, 7]. The former class of medications is indicated in for bacterial etiologies, while the latter can be used in some patients with allergic or atopic conjunctivitis that is refractory to treatment [8,9]. The indiscriminate use of these drugs can lead to complications and adverse ophthalmological reactions, such as antimicrobial resistance, worsening infections or increasing intraocular pressure, among others $[1,10]$.

The Colombian Health System offers universal coverage to the entire population through two regimes: a contributory one that is paid by workers and employers, and another that is subsidized by the state. The health system includes a benefit plan that covers a significant number of heterogeneous medications used in the management of patients with conjunctivitis. The objective of this study was to determine the prescription patterns of medications used in the treatment conjunctivitis in a population of Colombians covered by the health system.

\section{Materials And Methods}

A cross-sectional study was developed to establish the prescriptions used in the treatment of patients diagnosed with conjunctivitis based on a drug dispensing database that collects information from approximately 8.5 million people affiliated with the Colombian Health System through six health insurance companies, corresponding to approximately $30.0 \%$ of the active affiliated population of the contributory or payment regime and $6.0 \%$ of the statesubsidized regime and approximately $17.0 \%$ of the Colombian population during the study period.

Patients with a first diagnosis of conjunctivitis between April 1, 2020, and March 31, 2021, were identified based on the following International Classification of Diseases, version 10 (ICD-10) codes: allergic conjunctivitis (H01), bacterial conjunctivitis (A543, A740, H100), viral conjunctivitis (B301, B303, B308, B309), parasitic conjunctivitis $(\mathrm{H} 130, \mathrm{H} 131)$ and unspecified conjunctivitis $(\mathrm{H} 102, \mathrm{H} 103, \mathrm{H} 104, \mathrm{H} 108, \mathrm{H} 109, \mathrm{H} 132, \mathrm{H} 138$, P391). Patients of any sex and age who were treated through outpatient medical consultations were selected. Patients with a concomitant diagnosis of keratitis/corneal ulcer, blepharitis, stye, periorbital/orbital cellulitis, Sjögren's syndrome, stenosis and other lacrimal pathway disorders were excluded. Based on the drug consumption information for the affiliated population that was systematically obtained by the dispensing company (Audifarma SA), a database was designed that allowed the following groups of patient variables to be collected:

1. Sociodemographic: Age, sex, city of dispensation, type of affiliation with the Colombian Health System.

2. Clinical: The type of conjunctivitis (unspecified, bacterial, viral or allergic) and comorbidities were identified from the ICD-10 codes.

3. Pharmacological:

- Ophthalmological medications: N-acetyl aspartyl glutamic acid, antibiotics (azithromycin, bacitracin, ciprofloxacin, gatifloxacin, moxifloxacin, neomycin, polymyxin b, sulfacetamide, tobramycin), antihistamines (alcaftadine, bepotastine, epinastine, ketotifen, olopatadine), nonsteroidal antiOinflammatory 
drugs (diclofenac, bromfenac, nepafenac), antivirals (acyclovir, ganciclovir), glucocorticoids (dexamethasone, fluorometholone, loteprednol, prednisolone), mast cell membrane stabilizers (sodium cromoglycate), immunosuppressants (cyclosporine, tacrolimus), ocular lubricants/artificial tears (polyacrylic acid, polyvinyl alcohol, polyvinyl carboxylic acid, sodium cromoglycate), polyvinyl alcohol, carboxymethylcellulose, sodium hyaluronate, chondroitin sulfate, hydroxypropyl methylcellulose, polyethylene glycol, propylene glycol, sympathomimetics (phenylephrine, naphazoline, tetryzoline).

- Systemic drugs: Antibiotics (amoxicillin, ampicillin, azithromycin, cefadroxil, cephalexin, cephradine, ceftriaxone, ciprofloxacin, clarithromycin, clindamycin, dicloxacillin, doxycycline, erythromycin, norfloxacin) antihistamines (cetirizine, chlorpheniramine, desloratadine, diphenhydramine, fexofenadine, hydroxyzine, ketotifen, levocetirizine, loratadine), antiviral (acyclovir).

- Type of prescriber: General practitioner, optometrist, ophthalmologist, other specialty (internal medicine, pediatrics, geriatrics, etc.).

The protocol was approved by the Bioethics Committee of the Technological University of Pereira in the category of research without risk (Endorsement code: 02-210920). The ethical principles established by the Declaration of Helsinki were respected.

The data were analyzed with the statistical package SPSS Statistics, version 26.0 for Windows (IBM, USA). A descriptive analysis was performed using frequencies and proportions for qualitative-categorical variables. The normality of the continuous variables was evaluated using the Kolmogorov-Smirnov test, and continuous variables are reported as means and standard deviations and nonparametric variables are reported as medians and interquartile. The data are presented in the text and in tables.

\section{Results}

A total of 8708 patients with a diagnosis of conjunctivitis distributed in 140 different cities of Colombia were identified. A total of $59.3 \%$ ( $n=5160$ ) were women, and the median age was 44.7 years (interquartile range: $22.4-65.3$ years; range: $0.1-102.8$ years). A total of $21.6 \%$ ( $n=1877$ ) were younger than 18 years old, $23.4 \%(n=2041)$ were between 18 and 39 years old, $32.4 \%(n=2821)$ were between 40 and 64 years old, and $22.6 \%$ ( $n=1969)$ were 65 years old or older. A total of $70.4 \%(n=6130)$ of the patients lived in Bogotá $(n=1542 ; 17.7 \%)$, Cartagena $(n=857 ; 9.8 \%)$, Barranquilla ( $n=724 ; 8,3 \%)$, Popayán ( $n=719 ; 8.3 \%)$, Montería ( $n=650 ; 7.5 \%)$, Cali $(n=548 ; 6.3 \%)$, Sincelejo $(n=456 ; 5.2 \%)$, Armenia $(n=226 ; 2.6 \%)$, Manizales $(n=211 ; 2.4 \%)$ or Pereira $(n=197 ; 2.3 \%) ; 73.0 \%(n=6356)$ were affiliated with the contributory regime, and $27.0 \%(n=2352)$ were affiliated with the subsidized regime of the country's health system.

The most common etiology of conjunctivitis was unspecified $(n=4624 ; 53.1 \%)$, followed by allergic $(n=3259 ; 37.4 \%)$, bacterial $(n=636 ; 7.3 \%)$ and viral $(n=189$; $2.2 \%)$. Most of the patients were attended by general practitioners $(n=7274 ; 83.5 \%)$. A total of $97.0 \%(n=8444)$ of the patients received ophthalmic prescriptions, most commonly glucocorticoids ( $n=3507 ; 40.3 \%)$, followed by antibiotics ( $n=3284 ; 37.7 \%)$, antihistamines ( $n=2764) . ; 31.7 \%)$ and artificial tears $(n=1627 ; 18.7 \%)$. Systemic treatments for the management of conjunctivitis were prescribed in $14.3 \%(n=1243)$ of cases and mainly comprised antihistamines ( $n=997 ; 11.4 \%)$ and antibiotics $(n=293 ; 3.4$. \%). Table 1 shows the most commonly used ophthalmic and systemic medications for the management of patients with conjunctivitis. 
Table 1

Main ophthalmic and systemic drugs prescribed for the treatment of patients with conjunctivitis, Colombia.

\begin{tabular}{|c|c|c|}
\hline Drugs & $\mathrm{n}=8708$ & $\%$ \\
\hline Ophthalmic drugs & 8444 & 97.0 \\
\hline Olopatadine & 2274 & 26.1 \\
\hline Dexamethasone + neomycin + polymyxin $B$ & 2175 & 25.0 \\
\hline Carboxymethylcellulose & 706 & 8.1 \\
\hline Fluoromethalone & 643 & 7.4 \\
\hline Gentamicin & 597 & 6.9 \\
\hline Sodium cromoglycate & 514 & 5.9 \\
\hline Polyethylene glycol + propylene glycol & 322 & 3.7 \\
\hline Prednisolone + phenylephrine & 244 & 2.8 \\
\hline Hyaluronate + chondroitin & 219 & 2.5 \\
\hline Dexamethasone + tobramycin & 210 & 2.4 \\
\hline Hyaluronate & 203 & 2.3 \\
\hline Alcaftadine & 194 & 2.2 \\
\hline Prednisolone & 136 & 1.6 \\
\hline Ketotifen & 131 & 1.5 \\
\hline N-Acetyl Aspartyl Glutamic Acid & 114 & 1.3 \\
\hline Bepotastine & 104 & 1.2 \\
\hline Sulfacetamide & 100 & 1.1 \\
\hline Epinastine & 87 & 1.0 \\
\hline Moxifloxacin & 71 & 0.8 \\
\hline Tobramycin & 67 & 0.8 \\
\hline Other medications $(n=30)$ & 576 & 6.6 \\
\hline Systemic drugs & 1243 & 14.3 \\
\hline Loratadine & 412 & 4.7 \\
\hline Desloratadine & 253 & 2.9 \\
\hline Cephalexin & 146 & 1.7 \\
\hline Chlorpheniramine & 142 & 1.6 \\
\hline Cetirizine & 134 & 1.5 \\
\hline Amoxicillin & 49 & 0.6 \\
\hline Dicloxacillin & 39 & 0.4 \\
\hline Ciprofloxacin & 33 & 0.4 \\
\hline Ketotifen & 25 & 0.3 \\
\hline Diphenhydramine & 23 & 0.3 \\
\hline Other medications $(n=13)$ & 67 & 0.8 \\
\hline
\end{tabular}

A total of 489 different treatment regimens were found, and $51.6 \%(n=4489)$ of the patients received one of the following treatments: olopatadine ( $n=1737$; $19.9 \%)$, dexamethasone + neomycin + polymyxin ( $n=1453 ; 16.7 \%)$, carboxymethylcellulose $(n=481 ; 5.5 \%)$, fluorometholone $(n=477 ; 5.5 \%)$ and gentamicin $(n=341 ; 3.9 \%)$ (Table 2). Glucocorticoids associated with antibiotics were dispensed for $28.9 \%(n=2519)$ of patients with conjunctivitis, while glucocorticoids without antibiotics were dispensed for $11.3 \%(n=988)$, and antibiotics without glucocorticoids were used for $8.8 \%(n=765)$ of patients. 
Table 2

Comparison of some sociodemographic and pharmacological variables and comorbidities, according to the diagnosis of conjunctivitis, Colombia.

Variables

Total Unspecified

conjunctivitis

Allergic

conjunctivitis

Bacterial

conjunctivitis

Viral

$n=8708 \%$

$n=4624$

$n=3259$

conjunctivitis

$\mathrm{n}=\mathbf{1 8 9} \%$

\begin{tabular}{|c|c|c|c|c|c|c|c|c|c|c|}
\hline Women & 5160 & 59.3 & 2630 & 59.3 & 2056 & 63.1 & 367 & 57.7 & 107 & 56.6 \\
\hline Age, median (Interquartile range) & \multicolumn{2}{|c|}{$\begin{array}{l}44.7(22.4- \\
63.5)\end{array}$} & \multicolumn{2}{|c|}{$45.1(25.2-64.1)$} & \multicolumn{2}{|c|}{$45.1(17.5-63.2)$} & \multicolumn{2}{|c|}{$50.0(22.1-62.3)$} & \multicolumn{2}{|c|}{$\begin{array}{l}41.8(18.2- \\
60.3)\end{array}$} \\
\hline Chronic comorbidities & - & - & - & - & - & - & - & - & - & - \\
\hline Arterial hypertension & 2498 & 28.7 & 1421 & 30.7 & 858 & 26.3 & 176 & 27.7 & 43 & 22.8 \\
\hline Diabetes mellitus & 754 & 8.7 & 399 & 8.6 & 279 & 8.6 & 63 & 9.9 & 13 & 6.9 \\
\hline Glaucoma & 678 & 7.8 & 362 & 7.8 & 259 & 7.9 & 52 & 8.2 & 5 & 2.6 \\
\hline Hypothyroidism & 480 & 5.5 & 311 & 6.7 & 134 & 4.1 & 33 & 5.2 & 2 & 1.1 \\
\hline Allergic rhinitis & 480 & 5.5 & 248 & 5.4 & 211 & 6.5 & 16 & 2.5 & 5 & 2.6 \\
\hline Ophthalmic drug groups & 7465 & 85.7 & 3915 & 84.7 & 2949 & 90.5 & 477 & 75 & 124 & 65.6 \\
\hline Glucocorticoids & 3507 & 40.3 & 2208 & 47.8 & 860 & 26.4 & 326 & 51.3 & 113 & 59.8 \\
\hline Antibiotics & 3284 & 37.7 & 2172 & 47 & 548 & 16.8 & 415 & 65.3 & 149 & 78.8 \\
\hline Antihistamines & 2764 & 31.7 & 787 & 17.0 & 1870 & 57.4 & 90 & 14.2 & 17 & 9 \\
\hline Artificial tears & 1627 & 18.7 & 969 & 21.0 & 577 & 17.7 & 74 & 11.6 & 7 & 3.7 \\
\hline Mast cell membrane stabilizers & 563 & 6.5 & 268 & 5.8 & 256 & 7.9 & 29 & 4.6 & 10 & 5.3 \\
\hline Sympathomimetics & 300 & 3.4 & 167 & 3.6 & 116 & 3.6 & 16 & 2.5 & 1 & 0.5 \\
\hline N-Acetyl Aspartyl Glutamic Acid & 114 & 1.3 & 68 & 1.5 & 41 & 1.3 & 5 & 0.8 & 0 & 0.0 \\
\hline Immunosuppressants & 32 & 0.4 & 13 & 0.3 & 16 & 0.5 & 2 & 0.3 & 1 & 0.5 \\
\hline Non-steroidal anti-inflammatory drugs & 32 & 0.4 & 7 & 0.2 & 20 & 0.6 & 5 & 0.8 & 0 & 0.0 \\
\hline Antivirals & 3 & 0.0 & 3 & 0.1 & 0 & 0.0 & 0 & 0.0 & 0 & 0.0 \\
\hline Systemic drug groups & 1243 & 14.3 & 709 & 15.3 & 310 & 9.5 & 159 & 25.0 & 65 & 34.4 \\
\hline Antihistamines & 997 & 11.4 & 540 & 11.7 & 279 & 8.6 & 118 & 18.6 & 60 & 31.7 \\
\hline Antibiotics & 293 & 3.4 & 205 & 4.4 & 30 & 0.9 & 47 & 7.4 & 11 & 5.8 \\
\hline Antivirals & 7 & 0.1 & 4 & 0.1 & 2 & 0.1 & 1 & 0.2 & 0 & 0.0 \\
\hline Main management schemes & - & - & - & - & - & - & - & - & - & - \\
\hline Olopatadine & 1737 & 19.9 & 489 & 10.6 & 1204 & 36.9 & 32 & 5.0 & 12 & 6.3 \\
\hline Dexamethasone + neomycin + polymyxin & 1453 & 16.7 & 1108 & 24.0 & 139 & 4.3 & 138 & 21.7 & 68 & 36.0 \\
\hline Carboxymethylcellulose & 481 & 5.5 & 395 & 8.5 & 70 & 2.1 & 14 & 2.2 & 2 & 1.1 \\
\hline Fluoromethalone & 477 & 5.5 & 254 & 5.5 & 208 & 6.4 & 14 & 2.2 & 1 & 0.5 \\
\hline Gentamicin & 341 & 3.9 & 272 & 5.9 & 18 & 0.6 & 33 & 5.2 & 18 & 9.5 \\
\hline Sodium cromoglycate & 313 & 3.6 & 177 & 3.8 & 119 & 3.7 & 12 & 1.9 & 5 & 2.6 \\
\hline Polyethylene glycol + propylene glycol & 217 & 2.5 & 180 & 3.9 & 31 & 1.0 & 6 & 0.9 & 0 & 0.0 \\
\hline $\begin{array}{l}\text { Dexamethasone }+ \text { neomycin }+ \text { polymyxin }+ \\
\text { loratadine }\end{array}$ & 203 & 2.3 & 132 & 2.9 & 28 & 0.9 & 23 & 3.6 & 20 & 10.6 \\
\hline Prednisolone + phenylephrine & 166 & 1.9 & 117 & 2.5 & 34 & 1.0 & 14 & 2.2 & 1 & 0.5 \\
\hline Tobramycin + dexamethasone & 130 & 1.5 & 35 & 0.8 & 64 & 2.0 & 29 & 4.6 & 2 & 1.1 \\
\hline
\end{tabular}

As Table 2 shows, the proportion of women was higher for all types of conjunctivitis, and the median age among the groups was similar. Regarding the frequencies of prescriptions for various drug types, glucocorticoids and ophthalmic antibiotics predominated for both viral and bacterial conjunctivitis, while 
ophthalmic antihistamines were prescribed more frequently for allergic conjunctivitis, and artificial tears were prescribed most frequently for unspecified conjunctivitis. Systemic medications were used more often for viral and bacterial conjunctivitis (Table 2).

Table 3 shows the prescription patterns for the drug groups according to the prescriber and type of conjunctivitis. Notably, the majority of the ophthalmic glucocorticoids prescriptions were issued by general practitioners and optometrists. Similarly, ophthalmic antibiotics and systemic medications were prescribed mainly by general practitioners; in contrast, most of the prescriptions issued by ophthalmologists were for antihistamines and artificial tears. 
Table 3

Comparison between the type of prescriber and the groups of drugs formulated in the different types of conjunctivitis diagnosis, Colombia.

\begin{tabular}{|c|c|c|c|c|c|c|c|c|c|c|c|c|c|c|c|}
\hline \multirow[t]{2}{*}{ Variables } & \multicolumn{3}{|l|}{ Total } & \multicolumn{3}{|c|}{$\begin{array}{l}\text { Unspecified } \\
\text { conjunctivitis }\end{array}$} & \multicolumn{3}{|c|}{ Allergic conjunctivitis } & \multicolumn{3}{|c|}{ Bacterial conjunctivitis } & \multicolumn{3}{|c|}{ Viral conjunctivitis } \\
\hline & $n=8708$ & $\% *$ & $\% \star \star$ & $\mathrm{n}=4624$ & $\% *$ & $\% \star \star$ & $n=3259$ & $\% *$ & $\% \star \star$ & $\mathrm{n}=636$ & $\% *$ & $\% \star \star$ & $n=189$ & $\% *$ & $\% *$ \\
\hline $\begin{array}{l}\text { General practitioner } \\
\text { (prescriber) }\end{array}$ & 7274 & 83.5 & 100.0 & 3771 & 81.6 & 100.0 & 2756 & 84.6 & 100.0 & 570 & 89.6 & 100.0 & 177 & 93.7 & 10 \\
\hline Ophthalmic drugs & 7032 & 80.8 & 96.7 & 3667 & 79.3 & 97.2 & 2658 & 81.6 & 96.4 & 538 & 84.6 & 94.4 & 169 & 89.4 & 95 \\
\hline Corticosteroids & 3075 & 35.3 & 42.3 & 1909 & 41.3 & 50.6 & 765 & 23.5 & 27.8 & 295 & 46.4 & 51.8 & 106 & 56.1 & 59 \\
\hline Antibiotics & 3000 & 34.5 & 41.2 & 1999 & 43.2 & 53.0 & 476 & 14.6 & 17.3 & 384 & 60.4 & 67.4 & 141 & 74.6 & 79 \\
\hline Antihistamines & 2073 & 23.8 & 28.5 & 434 & 9.4 & 11.5 & 1549 & 47.5 & 56.2 & 77 & 12.1 & 13.5 & 13 & 6.9 & 7.3 \\
\hline Artificial tears & 1434 & 16.5 & 19.7 & 863 & 18.7 & 22.9 & 498 & 15.3 & 18.1 & 67 & 10.5 & 11.8 & 6 & 3.2 & 3.4 \\
\hline $\begin{array}{l}\text { Mast cell membrane } \\
\text { stabilizers }\end{array}$ & 432 & 5.0 & 5.9 & 181 & 3.9 & 4.8 & 215 & 6.6 & 7.8 & 26 & 4.1 & 4.6 & 10 & 5.3 & 5.6 \\
\hline Sympathomimetics & 251 & 2.9 & 3.5 & 146 & 3.2 & 3.9 & 91 & 2.8 & 3.3 & 13 & 2.0 & 2.3 & 1 & 0.5 & $0 . \epsilon$ \\
\hline $\begin{array}{l}\text { N-Acetyl Aspartyl } \\
\text { Glutamic Acid }\end{array}$ & 58 & 0.7 & 0.8 & 24 & 0.5 & 0.6 & 30 & 0.9 & 1.1 & 4 & 0.6 & 0.7 & 0 & 0.0 & $0 . \mathrm{C}$ \\
\hline Immunosuppressants & 26 & 0.3 & 0.4 & 9 & 0.2 & 0.2 & 14 & 0.4 & 0.5 & 2 & 0.3 & 0.4 & 1 & 0.5 & $0 . \epsilon$ \\
\hline $\begin{array}{l}\text { Non-steroidal } \\
\text { anti-inflammatory } \\
\text { drugs }\end{array}$ & 26 & 0.3 & 0.4 & 7 & 0.2 & 0.2 & 14 & 0.4 & 0.5 & 5 & 0.8 & 0.9 & 0 & 0.0 & $0 . \mathrm{C}$ \\
\hline Antivirals & 2 & 0.0 & 0.0 & 2 & 0.0 & 0.1 & 0 & 0.0 & 0.0 & 0 & 0.0 & 0.0 & 0 & 0.0 & $0 . \mathrm{C}$ \\
\hline Systemic drugs & 1166 & 13.4 & 16.0 & 660 & 14.3 & 17.5 & 294 & 9.0 & 10.7 & 148 & 23.3 & 26.0 & 64 & 33.9 & 36 \\
\hline Antihistamines & 933 & 10.7 & 12.8 & 502 & 10.9 & 13.3 & 263 & 8.1 & 9.5 & 109 & 17.1 & 19.1 & 59 & 31.2 & 33 \\
\hline Antibiotics & 281 & 3.2 & 3.9 & 195 & 4.2 & 5.2 & 30 & 0.9 & 1.1 & 45 & 7.1 & 7.9 & 11 & 5.8 & 6.2 \\
\hline Antivirals & 6 & 0.1 & 0.1 & 3 & 0.1 & 0.1 & 2 & 0.1 & 0.1 & 1 & 0.2 & 0.2 & 0 & 0.0 & $0 . \mathrm{C}$ \\
\hline $\begin{array}{l}\text { Optometrist } \\
\text { (prescriber) }\end{array}$ & 715 & 8.2 & 100.0 & 572 & 12.4 & 100.0 & 126 & 3.9 & 100.0 & 15 & 2.4 & 100.0 & 2 & 1.1 & 10 \\
\hline Ophthalmic drugs & 714 & 8.2 & 99.9 & 572 & 12.4 & 100.0 & 125 & 3.8 & 99.2 & 15 & 2.4 & 100.0 & 2 & 1.1 & 10 \\
\hline Antihistamines & 315 & 3.6 & 44.1 & 257 & 5.6 & 44.9 & 50 & 1.5 & 39.7 & 8 & 1.3 & 53.3 & 0 & 0.0 & $0 . \mathrm{C}$ \\
\hline Corticosteroids & 267 & 3.1 & 37.3 & 211 & 4.6 & 36.9 & 48 & 1.5 & 38.1 & 6 & 0.9 & 40.0 & 2 & 1.1 & 10 \\
\hline Antibiotics & 128 & 1.5 & 17.9 & 73 & 1.6 & 12.8 & 51 & 1.6 & 40.5 & 2 & 0.3 & 13.3 & 2 & 1.1 & 10 \\
\hline $\begin{array}{l}\text { Mast cell membrane } \\
\text { stabilizers }\end{array}$ & 84 & 1.0 & 11.7 & 78 & 1.7 & 13.6 & 6 & 0.2 & 4.8 & 0 & 0.0 & 0.0 & 0 & 0.0 & $0 . \mathrm{C}$ \\
\hline Artificial tears & 70 & 0.8 & 9.8 & 58 & 1.3 & 10.1 & 12 & 0.4 & 9.5 & 0 & 0.0 & 0.0 & 0 & 0.0 & $0 . C$ \\
\hline $\begin{array}{l}\text { N-Acetyl Aspartyl } \\
\text { Glutamic Acid }\end{array}$ & 30 & 0.3 & 4.2 & 29 & 0.6 & 5.1 & 1 & 0.0 & 0.8 & 0 & 0.0 & 0.0 & 0 & 0.0 & $0 . \mathrm{C}$ \\
\hline Sympathomimetics & 20 & 0.2 & 2.8 & 19 & 0.4 & 3.3 & 0 & 0.0 & 0.0 & 1 & 0.2 & 6.7 & 0 & 0.0 & $0 . \mathrm{C}$ \\
\hline $\begin{array}{l}\text { Non-steroidal anti- } \\
\text { inflammatory drugs }\end{array}$ & 5 & 0.1 & 0.7 & 0 & 0.0 & 0.0 & 5 & 0.2 & 4.0 & 0 & 0.0 & 0.0 & 0 & 0.0 & $0 . C$ \\
\hline Immunosuppressants & 2 & 0.0 & 0.3 & 2 & 0.0 & 0.3 & 0 & 0.0 & 0.0 & 0 & 0.0 & 0.0 & 0 & 0.0 & $0 . C$ \\
\hline Antivirals & 0 & 0.0 & 0.0 & 0 & 0.0 & 0.0 & 0 & 0.0 & 0.0 & 0 & 0.0 & 0.0 & 0 & 0.0 & $0 . C$ \\
\hline Systemic drugs & 5 & 0.1 & 0.7 & 4 & 0.1 & 0.7 & 1 & 0.0 & 0.8 & 0 & 0.0 & 0.0 & 0 & 0.0 & $0 . C$ \\
\hline Antihistamines & 4 & 0.0 & 0.6 & 3 & 0.1 & 0.5 & 1 & 0.0 & 0.8 & 0 & 0.0 & 0.0 & 0 & 0.0 & $0 . C$ \\
\hline Antibiotics & 1 & 0.0 & 0.1 & 1 & 0.0 & 0.2 & 0 & 0.0 & 0.0 & 0 & 0.0 & 0.0 & 0 & 0.0 & $0 . \mathrm{C}$ \\
\hline Antivirals & 0 & 0.0 & 0.0 & 0 & 0.0 & 0.0 & 0 & 0.0 & 0.0 & 0 & 0.0 & 0.0 & 0 & 0.0 & $0 . C$ \\
\hline
\end{tabular}

* Percentage calculated on the total of each column; ** Percentage calculated on the total of general practitioners, optometrists or ophthalmologists. 


\begin{tabular}{|c|c|c|c|c|c|c|c|c|c|c|c|c|c|c|c|}
\hline \multirow[t]{2}{*}{ Variables } & \multicolumn{3}{|l|}{ Total } & \multicolumn{3}{|c|}{$\begin{array}{l}\text { Unspecified } \\
\text { conjunctivitis }\end{array}$} & \multicolumn{3}{|c|}{ Allergic conjunctivitis } & \multicolumn{3}{|c|}{ Bacterial conjunctivitis } & \multicolumn{3}{|c|}{ Viral conjunctivitis } \\
\hline & $n=8708$ & $\% *$ & $\% * *$ & $n=4624$ & $\% *$ & $\% * \star$ & $n=3259$ & $\% *$ & $\% * *$ & $n=636$ & $\% *$ & $\% * \star$ & $n=189$ & $\% *$ & \%* \\
\hline $\begin{array}{l}\text { Ophthalmologist } \\
\text { (prescriber) }\end{array}$ & 489 & 5.6 & 100.0 & 128 & 2.8 & 100.0 & 337 & 10.3 & 100.0 & 17 & 2.7 & 100.0 & 7 & 3.7 & 10 \\
\hline Ophthalmic drugs & 489 & 5.6 & 100.0 & 128 & 2.8 & 100.0 & 337 & 10.3 & 100.0 & 17 & 2.7 & 100.0 & 7 & 3.7 & 10 \\
\hline Antihistamines & 321 & 3.7 & 65.6 & 56 & 1.2 & 43.8 & 256 & 7.9 & 76.0 & 5 & 0.8 & 29.4 & 4 & 2.1 & 57 \\
\hline Artificial tears & 114 & 1.3 & 23.3 & 40 & 0.9 & 31.3 & 67 & 2.1 & 19.9 & 6 & 0.9 & 35.3 & 1 & 0.5 & 14 \\
\hline Corticosteroids & 72 & 0.8 & 14.7 & 26 & 0.6 & 20.3 & 40 & 1.2 & 11.9 & 4 & 0.6 & 23.5 & 2 & 1.1 & 28 \\
\hline Antibiotics & 42 & 0.5 & 8.6 & 14 & 0.3 & 10.9 & 20 & 0.6 & 5.9 & 5 & 0.8 & 29.4 & 3 & 1.6 & 42 \\
\hline $\begin{array}{l}\text { Mast cell membrane } \\
\text { stabilizers }\end{array}$ & 28 & 0.3 & 5.7 & 3 & 0.1 & 2.3 & 25 & 0.8 & 7.4 & 0 & 0.0 & 0.0 & 0 & 0.0 & $0 . \mathrm{C}$ \\
\hline Sympathomimetics & 27 & 0.3 & 5.5 & 2 & 0.0 & 1.6 & 24 & 0.7 & 7.1 & 1 & 0.2 & 5.9 & 0 & 0.0 & $0 . \mathrm{C}$ \\
\hline $\begin{array}{l}\text { N-Acetyl Aspartyl } \\
\text { Glutamic Acid }\end{array}$ & 24 & 0.3 & 4.9 & 13 & 0.3 & 10.2 & 10 & 0.3 & 3.0 & 1 & 0.2 & 5.9 & 0 & 0.0 & $0 . \mathrm{C}$ \\
\hline Immunosuppressants & 3 & 0.0 & 0.6 & 2 & 0.0 & 1.6 & 1 & 0.0 & 0.3 & 0 & 0.0 & 0.0 & 0 & 0.0 & $0 . \mathrm{C}$ \\
\hline $\begin{array}{l}\text { Non-steroidal anti- } \\
\text { inflammatory drugs }\end{array}$ & 1 & 0.0 & 0.2 & 0 & 0.0 & 0.0 & 1 & 0.0 & 0.3 & 0 & 0.0 & 0.0 & 0 & 0.0 & $0 . \mathrm{C}$ \\
\hline Antivirals & 0 & 0.0 & 0.0 & 0 & 0.0 & 0.0 & 0 & 0.0 & 0.0 & 0 & 0.0 & 0.0 & 0 & 0.0 & $0 . \mathrm{C}$ \\
\hline Systemic drugs & 4 & 0.0 & 0.8 & 3 & 0.1 & 2.3 & 1 & 0.0 & 0.3 & 0 & 0.0 & 0.0 & 0 & 0.0 & $0 . \mathrm{C}$ \\
\hline Antihistamines & 3 & 0.0 & 0.6 & 2 & 0.0 & 1.6 & 1 & 0.0 & 0.3 & 0 & 0.0 & 0.0 & 0 & 0.0 & $0 . \mathrm{C}$ \\
\hline Antibiotics & 1 & 0.0 & 0.2 & 1 & 0.0 & 0.8 & 0 & 0.0 & 0.0 & 0 & 0.0 & 0.0 & 0 & 0.0 & $0 . \mathrm{C}$ \\
\hline Antivirals & 0 & 0.0 & 0.0 & 0 & 0.0 & 0.0 & 0 & 0.0 & 0.0 & 0 & 0.0 & 0.0 & 0 & 0.0 & $0 . \mathrm{C}$ \\
\hline
\end{tabular}

* Percentage calculated on the total of each column; ** Percentage calculated on the total of general practitioners, optometrists or ophthalmologists.

\section{Discussion}

This study allowed us to determine the prescription patterns of ophthalmic and systemic medications for the treatment of conjunctivitis in a group of patients affiliated with the Colombian Health System as evidence of drug use in the real world. These findings can be useful to help health care personnel; academics and scientists make decisions regarding the risks that their patients face and can contribute to strengthening the practices related to the rational use of antibiotics and glucocorticoids among physicians in an effort to reduce adverse drug reactions and ophthalmic complications in the country.

We observed that ophthalmic antibiotics were prescribed for more than one third of patients, including a large proportion of those with viral and unspecified conjunctivitis and a smaller proportion of patients with allergic conjunctivitis, for which clinical practice guidelines do not recommend the use of antibiotics [8, $9,11]$. However, the rate of antibiotics prescriptions for acute conjunctivitis is higher in countries such as the USA (58.0-72.7\%) [6, 12], Australia (74.0\%) [13], Holland (80.0\%) [14] and Belgium (89.4\%) [7] and lower in different Scandinavian countries (4.2-21.1\%) [15]. The present analysis found that the majority of prescriptions were issued by general practitioners, which is consistent with the reports of other publications [6, 12-14]. For example, in England, Everitt et al surveyed general practitioners and found that $95.0 \%$ prescribed antibiotics for the management of acute infectious conjunctivitis, but $58.0 \%$ of professionals believed that half of their patients had a viral infection [16]. The indiscriminate use of antibiotics can cause severe alterations in the ocular bacterial flora, which is essential for the prevention of ocular infections, and can be associated with an increase in antimicrobial resistance [10,17].

Differences were found in the most frequently used type of antibiotic. In the present report, a quarter of the patients were prescribed neomycin with polymyxin B and glucocorticoid; this is in contrast with other reports, in which other antibiotics predominated [7, 12-14, 18-21]. For example, the use of polymyxin B with trimethoprim predominated in the USA (53.4\%) [12], whereas it was prescribed with fusidic acid in the Netherlands (69.0\%) [14], levofloxacin in China (71.8\%) [18], chloramphenicol in Australia (50.8\%) [13], moxifloxacin in India (52.0-53.5\%) [20, 21] and tobramycin in Spain (66.1\%) [19] and Belgium (23.4\%) [7]. The differences in drug prescription patterns have been shown in other pharmacoepidemiological studies in the country, but in different clinical contexts [22-24]. These variations can be explained by the epidemiological heterogeneity among countries in terms of the etiology and resistance patterns of microorganisms, the characteristics of health systems, the accessibility and availability of drugs and the marketing strategies of the pharmaceutical industry [22, 23].

The inappropriate use of antibiotics for conjunctivitis with an etiology other than bacteria can have various causes. Professionals, especially general practitioners, may have difficulty distinguishing cases of viral and allergic conjunctivitis from bacterial cases because the three etiologies can present similar clinical characteristics, such as eye irritation, conjunctival injection and foreign body sensation [1, 4]. In addition, some prescribers may not have appropriate academic training for the correct diagnosis and treatment of acute conjunctivitis [25]. Similarly, the prescription of ophthalmic medications may be associated with sociodemographic characteristics of the patient, such as age, race, income, education level and comorbidities [6]. Additionally, patients may believe that antibiotics promotes faster recovery from the pathology and may therefore specifically seek such prescriptions from their doctor [15], and the unsubstantiated demand for these medications could lead to bias in the treating physician's diagnostic and therapeutic process. Furthermore, the large number of prescriptions 
for systemic medications to treat conjunctivitis is noteworthy given that these drugs be reserved for adjuvant therapy for conjunctivitis derived from sexually transmitted infections [1]. Finally, the absence of updated guidelines for the management of patients with conjunctivitis could contribute to the incorrect diagnosis and inadequate treatment of this pathology [26].

Another relevant aspect of this report was the large proportion of patients who received ophthalmic glucocorticoids, which are not recommended for the management of most cases of infectious conjunctivitis $[8,11]$. However, they can be used in short cycles for refractory cases of allergic and atopic conjunctivitis $[8,9]$. It is striking that almost $30.0 \%$ of the patients received antibiotics, which is consistent with other studies, such as those reported by De Loof et al in Belgium (30.5\%) [7], and is higher than that reported by Shekhawat et al in a study of more than 340,000 American patients, $20.0 \%$ of whom concomitantly used glucocorticoids and antibiotics [6], and by Yu et a/ in China, where this association was present in 17.5\% of cases [18]. The use of ophthalmic glucocorticoids should be limited due to the risk of complications and adverse drug reactions, since they increase the latency period of adenoviruses, prolong the course of viral conjunctivitis, aggravate herpes simplex virus infections, increase intraocular pressure and increase the risk of glaucoma and cataracts $[1,8,9,27,28]$ Therefore, due to the need for strict monitoring, these drug combinations should exclusively use by ophthalmologists and health personnel who have the necessary equipment to detect and prevent adverse eye reactions.

Some limitations in the interpretation of the results are recognized, since medical records were not accessed to verify the diagnosis of conjunctivitis or its etiology (allergic, infectious, other), severity and complications. Similarly, medications that the patients may have received that were prescribed outside the health system or were not delivered by the dispensing company were unknown. In addition, it is possible that some of the systemic prescriptions were used for pathologies other than conjunctivitis; however, these pathologies were not identified among the primary and secondary diagnoses listed in the database. However, the study included a significant number of patients who were distributed throughout most of the national territory and were covered by both the contributory and subsidized regimes of the country's health system.

With these findings, we can conclude that different types of conjunctivitis are being managed without following the recommendations of clinical practice guidelines. The results highlight the extensive use of antibiotics with ophthalmic glucocorticoids, which in many cases can be considered potentially inappropriate prescriptions. It is suggested that those responsible for health care and training provide continuing education measures and develop clinical practice guidelines specifically aimed at first-line health personnel, such as general practitioners, to promote better diagnostic processes and the more careful selection of available medications to reduce the risk of adverse drug reactions and the rates of antimicrobial resistance.

\section{Declarations}

Acknowledgements: To Soffy Claritza López for her work in obtaining the database. To Brahyan Osorio Velásquez and Jairo Daniel Corzo Romero for their collaboration in preparing the draft.

Funding: This work received no funding.

Competing interests: The authors declare that they have no conflict of interest.

Author Contributions: LFVR participated in the drafting, data collection, data analysis, description of results and discussion. MEMD participated in the drafting, data collection, data analysis, description of results and discussion. AGM participated in the drafting, description of results, and discussion of the article. DFLC participated in the drafting, description of results. JAOC participated in the drafting, description of results. MCOG participated in the drafting, description of results. DFMP participated in the drafting, description of results, and discussion of the article. JEMA participated in the drafting, data analysis, description of results, discussion, critical revision of the article, and evaluation of the final version of the manuscript.

Ethics approval: The protocol was approved by the Bioethics Committee of the Universidad Tecnológica de Pereira (Technological University of Pereira) in the category of "risk-free research" (approval number 02-210920). The principles established by the Declaration of Helsinki were respected.

Consent to participate. No applicable, is a retrospective observational study.

Consent to publish: all authors consent to participate

Data Availability Statement

Availability of data and material: protocolos.io

Code availability: dx.doi.org/10.17504/protocols.io.b4bxqspn

\section{References}

1. Azari AA, Barney NP (2014) Conjunctivitis: a systematic review of diagnosis and treatment. JAMA 311(1):95. https://. doi

2. Azari AA, Arabi A (2020) Conjunctivitis: A Systematic Review. J Ophthalmic Vis Res 15(3):372-395. https://. doi

3. Segal KL, Lai EC, Starr CE (2014) Management of Acute Conjunctivitis. Curr Ophthalmol Rep 2(3):116-123

4. Yeu E, Hauswirth S (2020) A Review of the Differential Diagnosis of Acute Infectious Conjunctivitis: Implications for Treatment and Management. Clin Ophthalmol 14:805-813. https://. doi

5. Chan VF, Yong AC, Azuara-Blanco A, Gordon I, Safi S, Lingham G, Evans J, Keel S (2021) A Systematic Review of Clinical Practice Guidelines for Infectious and Non-infectious Conjunctivitis. https://. Ophthalmic Epidemiol 1-10

Page $9 / 10$ 
6. Shekhawat NS, Shtein RM, Blachley TS, Stein JD (2017) Antibiotic Prescription Fills for Acute Conjunctivitis among Enrollees in a Large United States Managed Care Network. Ophthalmology 124(8):1099-1107. https://doi: 10.1016/j.ophtha.2017.04.034

7. Sapp JL, Alqarawi W, Maclntyre CJ, Tadros R, Steinberg C, Roberts JD, Laksman Z, Healey JS, Krahn AD (2020) Guidance on Minimizing Risk of DrugInduced Ventricular Arrhythmia During Treatment of COVID-19: A Statement from the Canadian Heart Rhythm Society. Can J Cardiol 36(6):948-951. https://. doi

8. Varu DM, Rhee MK, Akpek EK, Amescua G, Farid M, Garcia-Ferrer FJ, Lin A, Musch DC, Mah FS, Dunn SP (2019) American Academy of Ophthalmology Preferred Practice Pattern Cornea and External Disease Panel. Conjunctivitis Preferred Practice Pattern® Ophthalmology 126(1):P94-P169. https://doi: 10.1016/j.ophtha.2018.10.020

9. Optometric Clinical Practice Guideline: Care of the Patient with Conjunctivitis (2010) American Optometric Association. [Accessed on 24 Nov 2021]. Available from: https://www.sdeyes.org/docs/CPG-11.pdf

10. Dave SB, Toma HS, Kim SJ (2013) Changes in ocular flora in eyes exposed to ophthalmic antibiotics. Ophthalmology 120(5):937-941. https://. doi

11. National Institute for Health and Care Excellence. Conjunctivitis - infective (2021) [Accessed on 24 Nov 2021]. Available from: https://cks.nice.org.uk/topics/conjunctivitis-infective/

12. Frost HM, Sebastian T, Durfee J, Jenkins TC (2021) Ophthalmic antibiotic use for acute infectious conjunctivitis in children. J AAPOS 25(6):350. .e1350.e7 https://doi: 10.1016/j.jaapos.2021.06.006

13. Cherry MD, Tapley A, Quain D, Holliday EG, Ball J, Davey A, van Driel ML, Fielding A, Spike N, FitzGerald K, Magin P (2021) Antibiotic prescribing patterns of general practice registrars for infective conjunctivitis: a cross-sectional analysis. J Prim Health Care 13(1):5-14. https://. doi

14. Rietveld RP, ter Riet G, Bindels PJ, Schellevis FG, van Weert HC (2007) Do general practitioners adhere to the guideline on infectious conjunctivitis? Results of the Second Dutch National Survey of General Practice. BMC Fam Pract 8:54. https://. doi

15. Andersson J, Hofsli M, Gade UL, Heegaard S, Pottegård A (2018) Use of topical ocular antibiotics in young children: a Scandinavian drug utilization study. Acta Ophthalmol 96(8):789-794. https://. doi

16. Everitt H, Little P (2002) How do GPs diagnose and manage acute infective conjunctivitis? A GP survey. Fam Pract 19(6):658-660. https://doi: 10.1093/fampra/19.6.658

17. Al-Khalaileh W, Abu-Farha R, Wazaify M, Van Hout MC (2019) Ophthalmic drug abuse: An observational study from community pharmacies. Res Social Adm Pharm 15(8):943-948. https://doi: 10.1016/j.sapharm.2019.01.016

18. Yu Z, Zhu J, Jin J, Yu L, Han G (2021) Trends in Outpatient Prescribing Patterns for Ocular Topical Anti-Infectives in Six Major Areas of China, $2013-2019$. Antibiotics (Basel) 10(8):916. https://. doi

19. Gutiérrez-Abejón E, Herrera-Gómez F, Ayestarán-Martínez IJ, Álvarez FJ (2020) Trend in the use of topical ocular anti-infectives in a region of Spain between 2015 and 2019: a population-based registry study. Rev Esp Quimioter 33(6):453-458. https://. doi

20. Kauser H, Chopra D, Mukherjee S, Mohan P (2018) Pharmacoepidemiological Observational Study of Antimicrobial Use in Outpatients of Ophthalmology Department in North Indian Population. J Pharm Bioallied Sci 10(2):72-76. https://. doi

21. Supritha N, Mohapatra S, Rani RJ (2016) Prescription Pattern of Antibiotics and Susceptibility of The Pathogens in Infectious Conjunctivitis.Biomed Pharmacol J9(2)

22. Machado-Alba JE, Valladales-Restrepo LF, Gaviria-Mendoza A, Machado-Duque ME, Figueras A (2020) Patterns of Antibiotic Prescription in Colombia: Are There Differences between Capital Cities and Municipalities? Antibiotics (Basel) 9(7):389. https://. doi

23. Valladales-Restrepo LF, Constain-Mosquera CA, Álvarez-Amaya V, Machado-Alba JE (2021) Study of prescription-indication of tetracyclines in a population in Colombia. Fundam Clin Pharmacol Epub ahead of print https://. doi: 10.1111/fcp.12724

24. Valladales-Restrepo LF, Peña-Verjan NM, Vargas-Díaz K, Machado-Alba JE (2021) Potentially inappropriate prescriptions of antipsychotic and anticholinergic drugs in patients with Parkinson's disease. Neurodegener Dis Manag 11(5):361-371. https://. doi

25. Suman RK, Gore VS, Mohanty IR, Israni NA, Deshmukh YA (2015) Prescribing Patterns of Drugs Used For Treatment of Conjunctivitis in Ophthalmology Outpatient Department of Tertiary Care Hospital. Int J Health Sci Res 5:194-199

26. Giovanni Castaño M (2009) Guía para manejo de urgencias tomo II Bogotá: Imprenta Nacional de Colombia. : 370-7. [Accessed on 24 Nov 2021]. Available from: http://www.med-informatica.net/TERAPEUTICA-STAR/UrgenciasGuiaMPS2009_2_DocNewsNo19038DocumentNo10950.pdf

27. Holland EJ, Fingeret M, Mah FS (2019) Use of Topical Steroids in Conjunctivitis: A Review of the Evidence. Cornea 38(8):1062-1067. https://. doi

28. Sen P, Jain S, Mohan A, Shah C, Sen A, Jain E (2019) Pattern of steroid misuse in vernal keratoconjunctivitis resulting in steroid induced glaucoma and visual disability in Indian rural population: An important public health problem in pediatric age group. Indian J Ophthalmol 67(10):1650-1655. https://. doi 